Submitted to J. Inorg. Biochem.

\title{
Mitochondria-targeted ruthenium (II) polypyridyl complexes with benzofuran group for live cell imaging
}

Li Xu ${ }^{\text {a, }}$, Yu-Ying Liu ${ }^{\mathrm{a}}$, Liu-Ming Chen ${ }^{\mathrm{a}}$, Ye-Yi Xie ${ }^{\mathrm{a}}$, Jie-Xing Liang ${ }^{\mathrm{a}}$, Hui Chao ${ }^{\mathrm{b},{ }^{*}}$

${ }^{a}$ School of Chemistry and Chemical Engineering, Guangdong Pharmaceutical University, Zhongshan 528458, P. R. China

${ }^{b}$ MOE Key Laboratory of Bioinorganic and Synthetic Chemistry, School of Chemistry and Chemical Engineering, Sun Yat-Sen University, Guangzhou 510275, P. R. China.

* Corresponding author. Tel: +86 20 39352122; fax: +86 2039352129

E-mail address: xuli473@163.com(L. Xu), ceschh@mail.sysu.edu.cn(H.Chao) 


\begin{abstract}
Labeling and imaging mitochondria has attracted considerable interest because of its involvement in early stage apoptosis and necrotic cell death. Various highly specific and photostable fluorescent probes for mitochondria are in demand. In the present study, two novel $\mathrm{Ru}(\mathrm{II})$ polypyridine complexes $\mathbf{R u} \mathbf{1}$ and $\mathbf{R u} \mathbf{2}$ were developed to act as mitochondrial fluorescence probes. In comparison with the commercially available mitochondrial trackers, Ru1 possesses high mitochondria-specificity, superior photostability, high resistance to the loss of mitochondrial membrane potential and appreciable tolerance to environmental change, allowing imaging of the mitochondrial morphological changes over long periods of time. Combined results indicate that Ru1 may contribute to the future development of staining agents for organelle-selective imaging in living cells.
\end{abstract}

Keywords: Ru(II) complex; Mitochondria; Imaging; Probe; Photostability 


\section{Introduction}

Mitochondrion is a key organelle for cell survival due to its involvement in energy production and numerous vital physiological processes, such as cell apoptosis, differentiation, signal transduction and reactive oxygen species (ROS) generation [1-2]. Among these functions of mitochondria, the most prominent one is the ROS production, which leads to mitochondria-mediated apoptosis [3-4] as well as mitophagy [5]. It is believed that the size, number and morphology of mitochondria vary with the cell cycle, the metabolic state of the cell, and cellular development, differentiation and pathological states [6]. A recent work has revealed that the morphology and number of mitochondria could be directly related to many diseases, such as cancer [7-8] and neurodegenerative disorders [9]. Some reports also showed that proteins participating in apoptosis could affect the morphology of mitochondria [10-11]. Thus, imaging the mitochondrial morphological changes in live cells is of ultimate importance for clear explanation of biological processes in mitochondria as well as advancing early diagnosis and therapeutics of corresponding diseases.

To observe the biochemical events in living cells in a certain period of time, the fluorescent probes must tolerate a continual irradiation of light from fluorescent microscopes [12]. However, most conventional fluorescent dyes, especially commercialized probes, such as Rhodamine 123, MitoTracker ${ }^{\circledR}$ Green FM, and MitoTracker $^{\circledR}$ Red FM, fail to provide long-period tracking due to severe photobleaching [13-14]. In addition, organic dyes may be easily washed out when the stained cells lose their mitochondrial potential, which further hinders their biological 
applications [15]. To overcome these issues of organic fluorophores, phosphorescent heavy metal complexes have emerged as a distinctive class of intracellular stains and probes with many superior physicochemical properties. Among them, ruthenium(II) polypyridyl complexes offer particular scope, owing to their large stokes shifts, good water solubility, high chemical- and photo-stability, exceptional nonlinear optical properties, intense polarized luminescence, relatively long lifetimes and low cytotoxicity [16]. In recent years, some $\mathrm{Ru}(\mathrm{II})$ polypyridyl complexes have been investigated for the applications of live cell staining in different cell compartments, such as nucleus [17], cytoplasm [18] and mitochondria [19]. However, only a few examples of $\mathrm{Ru}(\mathrm{II})$ polypyridyl complexes succeeded in live cell imaging with low cytotoxicities and good water solubility. Yet, the vast potential of $\mathrm{Ru}(\mathrm{II})$ complexes as cell imaging probes still remains largely untapped.

It has been found that some phosphorescent heavy metal complexes containing the derivatives of imidazo[4,5-f][1,10]phenanthroline (PIP) as main ligands could accumulate in the mitochondria [18,20-21]. Motivated by these findings, in this work, we functionalized PIP by replacing one benzene ring with another benzofuran ring, in which DBFMP (DBFMP = 2-(2,3-dihydrobenzofuran-5-yl)-1H-imidazo-[4,5-f][1,10] phenanthroline) has a large planar aromatic area and possesses excellent photophysical properties. Herein, we aim to design novel Ru(II) complexes bearing the DBFMP ligand as mitochondria probes for real-time imaging which exhibit excellent luminescence, superior photostability, low cytotoxicities and good water solubility. We report the synthesis and characterization of two $\mathrm{Ru}(\mathrm{II})$ polypyridine 
complexes $\left[\mathrm{Ru}(\text { phen })_{2}(\mathrm{DBFMP})\right]^{2+}$ (phen $=1,10$-phenanthroline, DBFMP $=$ 2-(2,3-dihydrobenzofuran-5-yl)-1H-imidazo-[4,5-f][1,10] phenanthroline) Ru1 and $\left[\mathrm{Ru}(\mathrm{bpy})_{2}(\mathrm{DBFMP})\right]^{2+}\left(\right.$ bpy $=2,2^{\prime}$-bipyridine $)$ Ru2, including the X-ray crystal structure of Ru1. MitoTracker ${ }^{\circledR}$ Green FM co-staining and inductively coupled plasma mass spectrometry (ICP-MS) demonstrated that Ru1 could specifically illuminate mitochondria in live cells with good water solubility. The cellular uptake mechanism of Ru1 under different conditions, such as low temperature and in the presence of metabolic and endocytic inhibitors, was investigated. In addition, the photostability of Ru1 under photobleaching and $\mathrm{pH}$ fluctuation conditions was also investigated. Finally, the cytotoxicity of Ru1 was assessed in this study.

\section{Experimental}

\subsection{Materials and general instruments}

All reagents were purchased from commercial sources and used without further purification unless otherwise specified. All buffer components were of biological grade and were used as received. 3-(4,5-Dimethylthiazol-2-yl)-2,5-diphenyltetrazoliu bromide (MTT) was purchased from Sigma-Aldrich and was used without further purification. The commercially available mitochondrial imaging agent, MitoTracker ${ }^{\circledR}$ Green FM (MTG), was purchased from Invitrogen. The ligands cis- $\left[\mathrm{Ru}(\text { bpy })_{2} \mathrm{Cl}_{2}\right] \cdot 2 \mathrm{H}_{2} \mathrm{O} \quad[22], \quad$ cis- $\left[\mathrm{Ru}(\text { phen })_{2} \mathrm{Cl}_{2}\right] \cdot 2 \mathrm{H}_{2} \mathrm{O} \quad[22] \quad$ and 1,10-phenanthroline-5,6-dione [23] were prepared according to the previously reported methods. 
Microanalysis (C, H, and N) was carried out using a Perkin-Elmer 240Q elemental analyzer. Electrospray ionization mass spectra (ESI-MS) were recorded on a LCQ system (Finnigan MAT, USA). The expected and measured isotope distributions were compared. The ${ }^{1} \mathrm{H}$ NMR spectra were recorded on a Mercury-Plus 300 spectrometer (300 MHz). All chemical shifts are reported relative to tetramethylsilane (TMS). The UV-vis spectra were recorded on a Varian Cary 300 spectrophotometer. Steady-state emission experiments at room temperature were measured on an Edinburgh instrument FLSP-920 spectrometer with a Xe lamp as an excitation source. Luminescence lifetime studies were performed with an Edinburgh FLSP-920 photo-counting system using a hydrogen-filled lamp as the excitation source. Luminescence quantum yields of Ru1-Ru2 in PBS buffer solutions $(\mathrm{pH}=7.4)$ were measured with reference to $\left[\mathrm{Ru}(\mathrm{bpy})_{3}\right]^{2+}$.

\subsection{Synthesis}

\subsubsection{Synthesis of 2-(2,3-dihydrobenzofuran-5-yl)-1H-imidazo-[4,5-f][1,10]} phenanthroline (DBFMP)

A mixture of 2,3-dihydrobenzofuran-5-carboxaldehyde (0.22 g, $1.5 \mathrm{mmol})$, 1,10-phenanthroline-5,6-dione (0.32 g, $1.5 \mathrm{mmol})$, ammonium acetate $(2.31 \mathrm{~g}, 30$ mmol), and glacial acetic acid $\left(60 \mathrm{~cm}^{3}\right)$ was refluxed with stirring for $6 \mathrm{~h}$. The cooled solution was then diluted with water and neutralized with concentrated aqueous ammonia. The precipitate was collected and purified by column chromatography on silica gel (60-100 mesh) with ethanol as eluent to give the compound as a yellow 
powder. Yield: $0.36 \mathrm{~g}, 70 \%$. Anal. Calcd for $\mathrm{C}_{21} \mathrm{H}_{14} \mathrm{~N}_{4} \mathrm{O}$ : C, 74.54; H, 4.17; N, 16.56. Found: C, 74.94; H, 4.06; N, 16.72\%. FAB-MS: m/z=339 (M+1).

\subsubsection{Synthesis of $\left[R u(\text { phen })_{2}(D B F M P)\right] C l_{2}(\boldsymbol{R u} \mathbf{1})$}

A mixture of $c i s-\left[\mathrm{Ru}(\mathrm{phen})_{2} \mathrm{Cl}_{2}\right] \cdot 2 \mathrm{H}_{2} \mathrm{O}(0.28 \mathrm{~g}, 0.5 \mathrm{mmol})$ and DBFMP $(0.17 \mathrm{~g}$, $0.5 \mathrm{mmol})$ in ethanol $\left(60 \mathrm{~cm}^{3}\right)$ was refluxed under argon for $8 \mathrm{~h}$ to give a clear red solution. Upon cooling, a red precipitate was obtained by dropwise addition of saturated aqueous $\mathrm{NaClO}_{4}$ solution. The crude product was purified by column chromatography on a neutral alumina with a mixture of MeCN-toluene $(8: 1, \mathrm{v} / \mathrm{v})$ as eluent. Ru1 was then converted to the chloride salt by dissolving in a minimum amount of acetone, followed by the slow addition of a saturated solution of tetrabutylammonium chloride in acetone. The chloride salt was filtered, washed with acetone, and dried. Yield: $0.36 \mathrm{~g}, 72 \% . \mathrm{C}_{45} \mathrm{H}_{30} \mathrm{~N}_{8} \mathrm{Cl}_{2} \mathrm{O}_{9} \mathrm{Ru}: \mathrm{C}, 54.12 ; \mathrm{H}, 3.03 ; \mathrm{N}$, 11.22\%; Found: $\mathrm{C}, 53.89 ; \mathrm{H}, 3.15 ; \mathrm{N}, 11.45 \%$. ES-MS $\left[\mathrm{CH}_{3} \mathrm{CN}, \mathrm{m} / \mathrm{z}\right]: 998.1$ $\left(\left[\mathrm{M}-2 \mathrm{ClO}_{4}-\mathrm{H}\right]^{+}\right), 499.1\left(\left[\mathrm{M}-2 \mathrm{ClO}_{4}\right]^{2+}\right) .{ }^{1} \mathrm{H}$ NMR $\left(400 \mathrm{MHz}, \mathrm{DMSO}-\mathrm{d}_{6}\right): \delta 14.11(\mathrm{~s}$, 1H), $9.04(\mathrm{~d}, 2 \mathrm{H}, J=8.2 \mathrm{~Hz}), 8.77$ (d, 4H, $J=8.9 \mathrm{~Hz}), 8.40$ (s, 4H), 8.19(s, 1H), 8.12 (d, 2H, $J=4.8 \mathrm{~Hz}), 8.08(\mathrm{t}, 3 \mathrm{H}, J=10.5 \mathrm{~Hz}), 7.99$ (d, 2H, $J=4.4 \mathrm{~Hz}), 7.79-7.75(\mathrm{~m}$, $6 \mathrm{H}), 7.04(\mathrm{~d}, 1 \mathrm{H}, J=8.4 \mathrm{~Hz}), 4.67(\mathrm{t}, 2 \mathrm{H}, J=17.5 \mathrm{~Hz}), 3.37-3.30(\mathrm{~m}, 2 \mathrm{H})$.

\subsubsection{Synthesis of $\left[R u(b p y)_{2}(D B F M P)\right] C l_{2}(\mathbf{R u} 2)$}

This complex was synthesized by an identical method as described for Ru1, with cis-[Ru(bpy $\left.)_{2} \mathrm{Cl}_{2}\right] \cdot 2 \mathrm{H}_{2} \mathrm{O}$ in place of cis-[Ru(phen) $\left.)_{2} \mathrm{Cl}_{2}\right] \cdot 2 \mathrm{H}_{2} \mathrm{O}$ Yield: $0.32 \mathrm{~g}, 68 \%$. $\mathrm{C}_{41} \mathrm{H}_{30} \mathrm{~N}_{8} \mathrm{Cl}_{2} \mathrm{O}_{9} \mathrm{Ru}: \mathrm{C}, 51.80 ; \mathrm{H}, 3.18 ; \mathrm{N}, 11.79 \%$; Found: C, 51.60; H, 3.26; N, 
11.95\%. ES-MS $\left[\mathrm{CH}_{3} \mathrm{CN}, \mathrm{m} / \mathrm{z}\right]: 950.1\left(\left[\mathrm{M}-2 \mathrm{ClO}_{4}-\mathrm{H}\right]^{+}\right), 475.1\left(\left[\mathrm{M}-2 \mathrm{ClO}_{4}\right]^{2+}\right) .{ }^{1} \mathrm{H}$ NMR (400 MHz, DMSO-d $\left.)_{6}\right): \delta 14.11(\mathrm{~s}, 1 \mathrm{H}), 9.06(\mathrm{~d}, 2 \mathrm{H}, J=8.1 \mathrm{~Hz}), 8.87$ (d, 2H, $J$ $=8.2 \mathrm{~Hz}), 8.83(\mathrm{~d}, 2 \mathrm{H}, J=8.2 \mathrm{~Hz}), 8.21(\mathrm{t}, 3 \mathrm{H}, J=14.9 \mathrm{~Hz}), 8.10(\mathrm{t}, 3 \mathrm{H}, J=15.8 \mathrm{~Hz})$, $8.03(\mathrm{~d}, 2 \mathrm{H}, J=4.9 \mathrm{~Hz}), 7.91(\mathrm{dd}, 2 \mathrm{H}, J=5.3,5.2 \mathrm{~Hz}), 7.84(\mathrm{~d}, 2 \mathrm{H}, J=5.4 \mathrm{~Hz})$, 7.61-7.58 (m, 4H), $7.34(\mathrm{t}, 2 \mathrm{H}, J=13.2 \mathrm{~Hz}), 7.03(\mathrm{~d}, 1 \mathrm{H}, J=8.4 \mathrm{~Hz}), 4.67(\mathrm{t}, 2 \mathrm{H}, J=$ $17.4 \mathrm{~Hz}), 3.37-3.30(\mathrm{~m}, 3 \mathrm{H})$.

Caution: Perchlorate salts of metal compounds with organic ligands are potentially explosive, and only small amounts of the material should be prepared and handled with great care.

\subsection{X-ray crystallography}

Single crystal X-ray data of Ru1 was collected on an Oxford Diffraction Gemini R $\mathrm{CCD}$ diffractometer with $\mathrm{Cu} \mathrm{K} \alpha$ radiation $(\lambda=1.54178 \AA)$ at room temperture. Absorption corrections were applied with the SADABS program [24]. The structure solution and full-matrix least-squares refinement, based on $F^{2}$ for Ru1, were carried out with the SHELXS 97 and SHELXL 97 program packages, respectively [25]. Anisotropic thermal parameters were assigned to all non-hydrogen atoms. All hydrogen atoms were included in calculated positions and refined with isotropic thermal parameters riding on those of the parent atoms. Crystal parameters and details of the data collection and refinement were provided in Table 1. Selected bond lengths ( $)$ and bond angles (deg) were provided in Table 2. CCDC 1027624 (Ru1) contains

the supplementary crystallographic data for the present paper. Detailed 
crystallographic data can be obtained free of charge from The Cambridge Crystallographic Data Centre via www.ccdc.cam.ac.uk/data_request/cif.

\subsection{Cell culture}

The human cell lines HeLa (cervical cancer) and HEk293 (normal) were purchased from the American Type Culture Collection (ATCC). The cells were cultured in DMEM medium with $10 \%$ FBS and $1 \%$ antibiotic solution at $37{ }^{\circ} \mathrm{C}$ in a $5 \% \mathrm{CO}_{2}$ incubator.

\subsection{Cytotoxicity assay}

The cytotoxicities of the $\mathrm{Ru}(\mathrm{II})$ complexes were evaluated by the MTT assay using two different cell lines (HeLa and HEk 293). Cells were placed in 96-well plates at a density of $1 \times 10^{4}$ cells per well. After incubation for $24 \mathrm{~h}$, the cells were treated with increasing concentrations of the tested complexes for various times. Upon completion of the incubation, the culture media were discarded, and the cells were washed with PBS buffer solutions ( $\mathrm{pH} 7.4)$. Stock MTT dye solution $\left(20 \mu \mathrm{L}, 5 \mathrm{mg} \mathrm{mL}^{-1}\right)$ was then added to each well. After incubation for another $4 \mathrm{~h}$, the medium containing MTT was carefully removed from each well and $150 \mu \mathrm{L}$ of dimethyl sulfoxide was added into each well. The absorbance values of the wells were recorded on a microplate spectrophotometer at a wavelength of $490 \mathrm{~nm}$. The cell viability rate was estimated by the following equation:

Viable cells $(\%)=\left(O D_{\text {treated }} / O D_{\text {control }}\right) \times 100 \%$, where $O D_{\text {treated }}$ denotes the 
absorbance recorded in the presence of the complex, and $O D_{\text {control }}$ represents the absorbance of the control group recorded in the incubation medium.

\subsection{ICP-MS analysis}

HeLa cells were plated at a density of $1 \times 10^{5}$ cells per $\mathrm{ml}$ in $5 \mathrm{~mL}$ of DMEM medium, Ruthenium complexes $(25 \mu \mathrm{M})$ were added to the culture medium and incubated for $1 \mathrm{~h}$ at $37^{\circ} \mathrm{C}$. After digestion, HeLa cells were counted and divided into three portions. One portion: the nuclei were extracted using a nucleus extraction kit; the second portion: the cytoplasms were extracted using a cytoplasm extraction kit; the third portion: the mitochondria were extracted using a mitochondrial extraction kit (Shanghai Sangon Biological Engineering Technology \& Services Co. Ltd.). The samples were digested by $60 \% \mathrm{HNO}_{3}$ at room temperature overnight. Each sample was diluted with double-distilled water to obtain $2 \% \mathrm{HNO}_{3}$ sample solutions [26]. The ruthenium concentration in the three portions was determined by an inductively coupled plasma mass spectrometry (ICP-MS Thermo Elemental Co., Ltd.). The data were reported as the mean \pm standard deviation $(n=3)$.

\subsection{Inhibitor and temperature studies}

HeLa cells were detached from culture and treated with $50 \mathrm{mM}$ of 2-deoxy-D-glucose, $5 \mu \mathrm{M}$ of oligomycin, $50 \mathrm{mM}$ of $\mathrm{NH}_{4} \mathrm{Cl}, 100 \mu \mathrm{M}$ of chloroquine, and $10 \mu \mathrm{M}$ of carbonyl cyanide m-chlorophenylhydrazone (CCCP) in PBS buffer solutions $(\mathrm{pH}=7.4)$ for $1 \mathrm{~h}$. The cells were then washed with PBS and incubated with 
$25 \mu \mathrm{M}$ of Ru1 in PBS (pH 7.4) for $1 \mathrm{~h}$ at $4{ }^{\circ} \mathrm{C}, 25^{\circ} \mathrm{C}$ or $37^{\circ} \mathrm{C}$. The cells were washed with PBS and were then trypsinized and processed for flow cytometry analysis.

\subsection{Confocal luminescence imaging}

The HeLa cells were plated on a $35 \mathrm{~mm}$ cell culture dish (Corning) at a density of 2 $\times 10^{4}$ cells per dish. After incubation for a day at $37{ }^{\circ} \mathrm{C}$ under $5 \% \mathrm{CO}_{2}$, The cells were washed with PBS and then treated without or with $25.0 \mu \mathrm{M}$ of the $\mathrm{Ru}(\mathrm{II})$ complexes in PBS ( $\mathrm{pH}=7.4)$ for $1 \mathrm{~h}$ at $37^{\circ} \mathrm{C}$. After washing the cells with PBS buffer three times to remove the remaining probes, the HeLa cells were further incubated with Mito-tracker (MTG) for $30 \mathrm{~min}$. The cells were washed three times carefully with PBS buffer solutions and then subjected to confocal microscopy. Fluorescence microscope images were captured on a laser confocal microscope (Nikon A1R). The laser excitation wavelength was $405 \mathrm{~nm}$ for Ru1 and $488 \mathrm{~nm}$ for MTG, and the emission signal was collected at $600 \pm 20 \mathrm{~nm}$ (for Ru1), $520 \pm 20 \mathrm{~nm}$ (for MTG).

\section{Results and discussion}

\subsection{Synthesis and characterization}

The ligand DBFMP was synthesized through the condensation of 1,10-phenanthroline-5,6-dione, 2,3-dihydrobenzofuran-5-carboxaldehyde and ammonium acetate in refluxing glacial acetic acid for 6 h. The complexes Ru1 and Ru2 (Fig. 1) were obtained in relatively high yields (75\%) by the direct reaction of DBFMP with appropriate molar ratios of the precursor complexes cis- $\left[\mathrm{Ru}(\mathrm{N}-\mathrm{N})_{2} \mathrm{Cl}_{2}\right](\mathrm{N}-\mathrm{N}=$ bpy, 
phen) in ethanol. All of these complexes were purified by aluminium oxide chromatography with toluene and acetonitrile as the eluents, and characterized by elemental analysis, ${ }^{1} \mathrm{H}$ NMR and ES-MS. When synthesized as their chloride salt, Ru1-Ru2 were found to be water soluble. Single crystals of the Ru1 were obtained by slowly evaporating the solvent at room temperature. The crystal data and structural refinements are shown in Table 1. Selected bond lengths and angles are listed in Table 2. The crystal structure of Ru1 was presented in Figure S1 (Supporting Information). Ru1 was crystallized in the $P-1$ triclinic space group. As expected, Ru(II) possesses a distorted octahedral coordination sphere as a consequence of the small bite angles of the bidentate ligand, with a bite angle of $79.97^{\circ}$ averaged over the three bidentate ligands. The mean $\mathrm{Ru}-\mathrm{N}$ bond length $(2.063 \AA)$ is comparable with those published $\mathrm{Ru}(\mathrm{II}) \quad$ complexes $\quad\left(2.064 \AA\right.$ for $\quad\left[\mathrm{Ru}(\mathrm{phen})_{2}(\mathrm{dpq})\right]^{2+}, \quad \mathrm{dpq}=$ dipyrido[3,2-d:2',3'-f]quinoxaline) [27]; $2.076 \AA$ for $\left[\mathrm{Ru}(\mathrm{bpy})_{2}(\mathrm{pzta})\right]^{2+}$, pzta $=$ 6-(pyrzin2-yl)-1,3,5-triazine-2,4-diamine [28]. The phenyl ring, the imidazo[4,5-f]-1,10-phenanthroline ring and the furan ring are approximately coplanar. As a result, DBFMP has a large planar aromatic area and exhibits excellent luminescence.

\subsection{Photophysical studies}

The photophysical properties of Ru1 and Ru2 have been investigated by UV-vis absorption and emission spectroscopy (Fig. 2). The UV-vis absorption spectra of Ru1 and Ru2 in PBS buffer solutions ( $\mathrm{pH}=7.4)$ were shown in Fig. 2a. The electronic 
absorption spectra show an absorption band at $459 \mathrm{~nm}$ for Ru1 and $455 \mathrm{~nm}$ for Ru2, which are assigned to a metal to ligand charge transfer (MLCT) transition. The bands at $286 \mathrm{~nm}$ for $\mathbf{R u} \mathbf{1}$ and 285 and $263 \mathrm{~nm}$ for $\mathbf{R u} 2$ are attributed to the $\pi-\pi^{*}$ intraligand transitions. The emission spectra of Ru1 and Ru2 were recorded in PBS buffer solutions $(\mathrm{pH}=7.4)$ at room temperature (Fig. 2b), and the corresponding photophysical data were listed in Table S1. When excited into the MLCT absorbance, a stronger intense emission band for Ru1 was observed at $612 \mathrm{~nm}$ with a quantum yield of 0.50 that is slightly higher than that of the $\mathbf{R u} 2(\Phi=0.48)$, using $\left[\mathrm{Ru}(\mathrm{bpy})_{3}\right]^{2+}$ as a standard [29]. In addition, the excited-state lifetime $(\tau)$ at room temperature are fitted to single exponential decay function for the complexes, and the data suggested that Ru1 (598.4 ns) possess longer fluorescence lifetime than Ru2 (500.2 ns). In a control experiment, the photophysical properties of the complex $\left[\mathrm{Ru}(\mathrm{phen})_{2}(\mathrm{pip})\right]^{2+}$ showed an absorption in the visible region with a maximum wavelength at $455 \mathrm{~nm}$, a triplet state emission at $609 \mathrm{~nm}\left(\lambda_{\mathrm{ex}}=455 \mathrm{~nm}\right)$ with a lifetime of $232.5 \mathrm{~ns}$. The emission quantum yield $(\Phi)$ was determined as 0.02 for $\left[\mathrm{Ru}(\mathrm{phen})_{2}(\mathrm{pip})\right]^{2+}$. The results showed that stronger fluorescence possessed by Ru1 may be attributed to larger planar aromatic area [30].

\subsection{Cellular uptake and localization studies}

In order to investigate the subcellular location of Ru1 and Ru2, inductively coupled plasma mass spectrometry (ICP-MS) experiments were employed to quantify the amounts of ruthenium presenting in the nucleus, mitochondria and the cytoplasm 
of a Ru complex-stained cell (Fig. 3). The ICP-MS results of Ru1 showed a substantial difference among the nucleus (0.42 pg Ru per cell), mitochondria (4.30 pg $\mathrm{Ru}$ per cell) and cytoplasm ( $4.85 \mathrm{pg} \mathrm{Ru}$ per cell), suggesting that more than $80 \%$ of ruthenium was distributed in the cell mitochondria. However, HeLa cells treated with $\mathbf{R u} 2$ resulted in an increase in $\mathrm{Ru}$ concentration in the cytoplasm and low levels of $\mathrm{Ru}$ within the mitochondria. The difference in the cellular distributions of Ru1 and Ru2 was possibly caused by the different chemical structures of the ancillary ligands. According to the results of ICP-MS experiments, Ru1 exhibited higher specific location in mitochondria compared with Ru2. Thus, Ru1 was used for further investigation regarding as mitochondria probes.

To test the feasibility of Ru1 to target mitochondria, we performed co-localization imaging experiments using Ru1 and MitoTracker® dyes to co-label HeLa cells. The incubation of $25 \mu \mathrm{M}$ Ru1 in DMEM with $10 \%$ FBS for $1 \mathrm{~h}$ was followed by the removal of excess complex by washing with PBS three times and incubating using 50 $n \mathrm{M}$ MTG for $30 \mathrm{~min}$. As Fig. 4 shows, under these conditions, the confocal images of Ru1 almost completely overlay with that of MitoTracker ${ }^{\circledR}$ Green FM, suggesting that Ru1 can selectively accumulate into cellular mitochondria of living cells. The imaging results revealed that Ru1 exhibited the capacity for fast crossing of the membrane $(1 \mathrm{~h})$ and selective accumulation in mitochondria in HeLa cells at a low concentration $(25 \mu \mathrm{M})$. The staining conditions of Ru1 offer advantages over those other similar $\mathrm{Ru}(\mathrm{II})$ complexes which target mitochondria [30-31].

We next evaluated the tolerance ability of the $\mathrm{Ru}(\mathrm{II})$ complex to the changes in the 
mitochondrial membrane potential $(\Delta \Psi \mathrm{m})$. Carbonyl cyanide 3-chlorophenylhydrazone (CCCP) is the uncoupler that can cause rapid acidification of the mitochondria, dysfunction of ATP synthase and decrease of membrane potential, and thus was used to treat the cells prior to the staining procedure [32]. Staining with MitoTracker Green FM, which is a mitochondrial probe whose uptake is independent of membrane potential, resulted in the same results (Fig. 5) in the presence or absence of CCCP [33-34]. The staining of Ru1 also showed no difference in the presence or absence of CCCP (Fig. 5), suggesting that the staining properties of Ru1 are also independent of the mitochondrial membrane potential.

\subsection{Mechanisms of cellular uptake}

In order to investigate the mechanism of cellular uptake, the behaviour of Ru1 was examined by flow cytometry under different temperatures as well as in the presence of metabolic and endocytic inhibitors. Fig. S2A and B (ESI $\dagger$ ) showed that the cellular uptake was suppressed in cases when the cells were incubated with the complex at 4 ${ }^{\circ} \mathrm{C}$ or $25^{\circ} \mathrm{C}$. In addition, the intracellular luminescence was weaker than that at $25^{\circ} \mathrm{C}$ when the incubation temperature was set to $4{ }^{\circ} \mathrm{C}$, indicating that the complex enters cell through an energy-dependent pathway. To clearly delineate that Ru1 was taken up via an energy-dependent mechanism, HeLa cells were pretreated with the metabolic inhibitors 2-deoxy- $D$-glucose and oligomycin [35-36]. Metabolic inhibitors deplete the cell of energy, resulting in the diminished uptake of molecules. As showed in Fig. S2F, the intracellular luminescence was diminished, which indicates that the 
complex enters cells through an energy-dependent pathway. This conclusion was supported by the low temperature incubation results. Endocytosis inhibitors (chloroquine and $\mathrm{NH}_{4} \mathrm{Cl}$ ) were used to examine whether the $\mathrm{Ru}(\mathrm{II})$ complex enters cells by endocytosis processes because endocytosis is a well-known energy-dependent transmembrane mechanism [37]. After treating with these inhibitors (Fig. S2D and E, ESI $\dagger$ ), the cellular uptake was not significantly altered, which indicates that the $\mathrm{Ru}(\mathrm{II})$ complex was not taken up by cells through the endocytosis pathway. The previously mentioned data indicated that Ru1 was taken up by living cells via an energy-dependent, non-endocytotic pathway.

\subsection{The photostability}

High photostability is a very important property for probes in bioimaging applications and can facilitate long-term observations. The photostabilities of the Ru1 was compared with commercially available MitoTracker Green, through quantitatively examination in living HeLa cells by photobleaching with a confocal microscope (Nikon A1R). HeLa cells were stained with $25.0 \mu \mathrm{M}$ of Ru(II) complex for $1 \mathrm{~h}$ and then were further stained with $50 \mathrm{nM}$ of MTG for another $20 \mathrm{~min}$. With the help of a power meter, the excitation power from the $488 \mathrm{~nm}$ channel of the microscope and exposure time during imaging was unified and used to irradiate the $\mathrm{Ru}(\mathrm{II})$ complex and MTG co-stained cells. The initial intensity from the first scan of the co-stained cells was normalized, and the percentages of the fluorescence signal loss was calculated. Fig. 6 shows that the fluorescence intensity of MitoTracker Green 
decreased to $\sim 25 \%$ after $80 \mathrm{~s}$ (and to $7 \%$ after $180 \mathrm{~s}$ ) of irradiation. In contrast, $85 \%$ fluorescence intensity of the $\mathrm{Ru}(\mathrm{II})$ complex was kept after $180 \mathrm{~s}$ of irradiation, suggesting greater photostability of the $\mathrm{Ru}(\mathrm{II})$ complex in comparison to MitoTracker Green. For a dye applied to biological situations, it should tolerate a wide range of $\mathrm{pH}$ [18]. Here, the effect of $\mathrm{pH}$ on the luminescent stability of the $\mathrm{Ru}(\mathrm{II})$ complex was also investigated, and the $\mathrm{pH}$ titration curve revealed that the effect of $\mathrm{pH}$ on the luminescence intensity was small in the range of $\mathrm{pH} 4-10$ (Fig. S3).

\subsection{Cell viability}

Cytotoxicity of the probes is one of the major concerns in bioimaging applications. The cytotoxicity of Ru1 against HeLa cells and HEk293 cells has been conducted by the MTT assay. After treatment of HeLa and HEk293 cell lines for 48 hours with Ru1 in the range of concentration $(12.5 \rightarrow 400 \mu \mathrm{M})$, the inhibitory percentage against growth of cancer cells was determined. The cell survival rate (\%) obtained with continuous exposure for 48 hours is depicted in Fig. S4. The cytotoxicity of Ru1 was found to be concentration dependent. The $\mathrm{IC}_{50}$ values for Ru1 in HeLa and HEk293 cell lines were $175.5 \mu \mathrm{M}$ and $201.2 \mu \mathrm{M}$, respectively. Moreover, the commercial mitochondrial imaging agent MTG was used as a control at their working concentrations (50 nM). Fig. 7 (HeLa) and Fig. S5 (HEk293) displayed that a time-dependent cytotoxicity study was carried out on Ru1 at $25.0 \mu \mathrm{M}$ over $0-24 \mathrm{~h}$ to evaluate cell viabilities. In general, Ru1 exhibited as high as 95\% of cell viability against the tested cells after incubation for $24 \mathrm{~h}$ at $25.0 \mu \mathrm{M}$. These results indicate that 
Ru1 presented relatively low toxicities under our experimental conditions of living cells imaging $(25.0 \mu \mathrm{M}$, treated for $1 \mathrm{~h})$.

\section{Conclusions}

Two new water-soluble $\mathrm{Ru}(\mathrm{II})$ polypyridine complexes, Ru1-Ru2, have been designed and synthesized. Ru1 was demonstrated to show specificity to mitochondria. In addition, it possesses superior photostability, low cytotoxicity at the imaging concentration, excellent $\mathrm{pH}$ resistance and high resistance to the loss of mitochondrial membrane potential. As a result, Ru1 is believed to have great potential as biocompatible imaging agent for mitochondrial targeting. These promising findings provide great encouragement to pursue the investigations toward the use of inert $\mathrm{Ru}$ complexes in cellular imaging research.

\section{Acknowledgements}

This work was supported by the National Science of Foundation of China (No. 21301034) and the National Science of Foundation of Guangdong Province (S2013040014083). 


\section{References}

[1] C.D. Folmes, P.P. Dzeja, T.J. Nelson, A. Terzic, Circ Res. 110 (2012) 526-529.

[2] A.T. Hoye, J.E. Davoren, P. Wipf, M.P. Fink, V.E. Kagan, Acc. Chem. Res. 41 (2008) 87-97.

[3] B.C. Dickinson, D. Srikun, C.J. Chang, Curr. Opin. Chem. Biol. 14 (2010) 50-56.

[4] B.C. Dickinson, C.J. Chang, J. Am. Chem. Soc. 130 (2008) 9638-9639.

[5] Y. Wang, Y. Nartiss, B. Steipe, G.A. McQuibban, P.K. Kim. Autophagy. 8 (2012) $1462-1476$.

[6] C. Rouiller, Int. Rev. Cytol. 9 (1960) 227-292.

[7] V. Gogvadze, S. Orrenius, B. Zhivotovsky, Trends Cell Biol. 18 (2008) 165-173.

[8] G. Kroemer, Oncogene. 25 (2006) 4630-4632.

[9] G. Masanta, C.H. Heo, C.S. Lim, S.K. Bae, B.R. Cho, H.M. Kim, Chem. Commun. 48 (2012) 3518-3520.

[10] M. Karbowski, R.J. Youle, Cell Death Differ. 10 (2003) 870-880.

[11] S. Gandre-Babbe, A.M. van der Bliek, Mol Biol Cell. 19 (2008) 2402-2412.

[12] C.W.T. Leung, Y.N. Hong, S.J. Chen, E.G. Zhao, J.W.Y. Lam, B.Z. Tang, J. Am.Chem. Soc. 135 (2013) 62-65.

[13] S. Lee, X.Y. Chen, ChemBioChem. 12 (2011) 2120-2121.

[14] A.M. Derfus, W.C.W. Chan, S.N. Bhatia, Adv. Mater. 16 (2004) 961-966.

[15] Y. Chen, L. Qiao, L. Ji, H. Chao, Biomaterials. 35 (2014) 2-13.

[16] V. Balzani, G. Bergamini, F. Marchioni, P. Ceroni, Coord. Chem. Rev. 250 (2006) 1254-1266. 
[17] V. Rajendiran, M. Palaniandavar, V.S. Periasamy, M.A. Akbarsha, J. Inorg. Biochem. 104(2) (2010) 217-220.

[18] W. Xu, J. Zuo, L. Wang, L. Ji, H. Chao, Chem. Commun. 50 (2014) 2123-2125.

[19] A. Martin, A. Byrne, C.S. Burke, R.J. Forster, T.E. Keyes, J. Am. Chem. Soc. 136(43) (2014) 15300-15309.

[20] T.F. Chen, Y.N. Liu, W.J. Zheng, J. Liu, Y.S. Wong, Inorg. Chem. 49 (2010) $6366-6368$.

[21] C.Z. Jin, J.P. Liu, Y. Chen, G.Y. Li, R.L. Guan, P.Y. Zhang, L.N. Ji, H. Chao, Dalton Trans. 44 (2015) 7538-7547.

[22] B.P. Sullivan, D.J. Salmon, T.J. Meyer, Inorg. Chem. 17 (1978) 3334-3341.

[23] M. Yamada, Y. Tanaka, Y. Yoshimoto, S. Kuroda, I. Shimao, Bull. Chem. Soc. Jpn. 65 (1992) 1006-1011.

[24] R. Blessing, Acta Crystallogr. Sect. A 51 (1995) 33-38.

[25] G.M. Sheldrick, SHELXS 97, program for X-ray crystal structure determination. University of Göttingen 1997.

[26] A.E. Egger, C. Rappel, M.A. Jakupec, C.G. Hartinger, P. Heffeter, B.K. Keppler, J. Anal. Spectrom. 24 (2009) 51-61.

[27] J.G. Liu, Q.L. Zhang, X.F. Shi, L.N. Ji, Inorg. Chem. 40 (2001) 5045-5050.

[28] Y. Chen, W.C. Xu, J.F. Kou, B.L. Yu, X.H. Wei, H. Chao, L.N. Ji, Inorg. Chem. Comm. 13 (2010) 1140-1143.

[29] K. Nakamaru, Bull. Chem. Soc. Jpn. 55 (1982) 2697-2705.

[30] Y. Ding, Q. Wu, K.D. Zheng, L.K. An, X.Y. Hu, W.J. Mei, Rsc Adv. 5 (2015) 
$63330-63337$.

[31] H.Z. Ke, H.D. Wang, W. K. Wong, N.K. Mak, D.W.J. Kwong, K.L. Wong, H.L. Tam, Chem. Commun. 46 (2010) 6678-6680.

[32] T. Nishikawa, D. Edelstein, X.L. Du, S. Yamagishi, T. Matsumura, Y. Kaneda, M.A. Yorek, D. Beebe, P.J. Oates, H.P. Hammes, I. Giardino, M. Brownlee, Nature. 404 (2000) 787-790.

[33] Y. Kawazoe, H. Shimogawa, A. Sato, M. Uesugi, Angew. Chem. Int. Ed. 50 (2011) 5478-5481.

[34] S. Versari, A.M. Villa, A. Villa, S.M. Doglia, G.A. Pagani, S. Bradamante, J. Biomed. Opt. 11 (2006) 34014.

[35] C.A. Puckett, J.K. Barton, Biochemistry. 47 (2008) 11711-11716.

[36] K.Y. Zhang, H.W. Liu, T.T.H. Fong, X.G. Chen, K.K.W. Lo, Inorg. Chem. 49 (2010) 5432-5443.

[37] S.E. Gratton, P.A. Ropp, P.D. Pohlhaus, J.C. Luft, V.J. Madden, M.E. Napier, Proc. Natl. Acad. Sci. U. S. A. 105 (2008) 11613-11618. 


\section{Figure and Table captions:}

Fig. 1 The structure of complexes Ru1 and Ru2.

Fig. 2 (a) UV-vis absorption spectra of Ru1-Ru2 $(10 \mu \mathrm{M})$ in PBS buffer solutions $(\mathrm{pH}=7.4)$. (b) Room temperature photoluminescence spectra of Ru1-Ru2 $(10 \mu \mathrm{M})$ in PBS buffer solutions $(\mathrm{pH}=7.4)$.

Fig. 3 ICP-MS quantification of the internalized Ru by the HeLa cells. HeLa cells were treated with $25 \mu \mathrm{M}$ of Ru1-Ru2 at $37{ }^{\circ} \mathrm{C}$ for $1 \mathrm{~h}$. Nuclei (Nuc.), mitochondria (Mito.) and cytoplasm (Cyto.) were extracted using the mitochondrial isolation and nuclear isolation kits (Pierce, Thermo). The value of the internalized ruthenium for the whole cell (Whole) was obtained by adding the values for the nuclei and the cytoplasm.

Fig. 4 Confocal fluorescence image, bright field image and their overlay of living HeLa cells incubated with $25 \mu \mathrm{M}$ of $\mathbf{R u 1}$ in PBS $(\mathrm{pH}=7.4)$ for $1 \mathrm{~h}$ at $37^{\circ} \mathrm{C}$, followed by $50 n \mathrm{M}$ of MTG, respectively. (A) confocal fluorescence image of MTG; (B) confocal fluorescence image of Ru1; (C) overlay of A and B; (D) bright field image; (E) overlay of A, B and D.

Fig. 5 Confocal fluorescence images of the cells were incubated in the absence or presence of $10 \mu \mathrm{M}$ CCCP for $1 \mathrm{~h}$, and then stained with 50 $n \mathrm{M}$ MTG for $30 \mathrm{~min}$ and $25 \mu \mathrm{M}$ Ru1 for $1 \mathrm{~h}$. 
Fig. 6 The anti-bleaching properties of Ru1. HeLa cells were treated with 25 $\mu \mathrm{M}$ of Ru1, followed by $50 n \mathrm{M}$ of MTG. (a) Intensity loss (\%) of the fluorescence of Ru1 and MTG with an increasing bleaching time. (b) Confocal fluorescence images of cells stained with Ru1 and MTG with an increasing bleaching time (180 s).

Fig. 7 In vitro cell viability of HeLa cells incubated with $25 \mu \mathrm{M}$ of Ru1, 50 $n \mathrm{M}$ of MTG at $37^{\circ} \mathrm{C}$ for different amounts of time, respectively. 
Table 1 Crystal data and structure refinement for Ru1.

Table 2 Selected bond lengths $(\AA)$ and angles $\left({ }^{\circ}\right)$ for Ru1. 


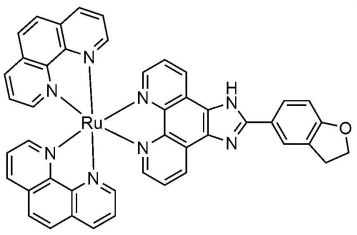

1

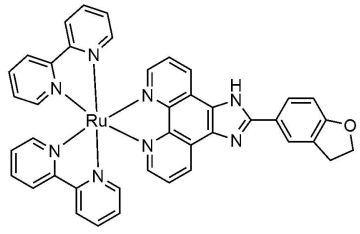

2 


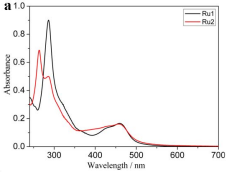

b

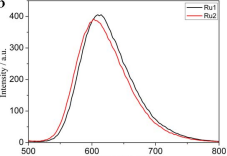

Wavelength / $\mathrm{nm}$ 


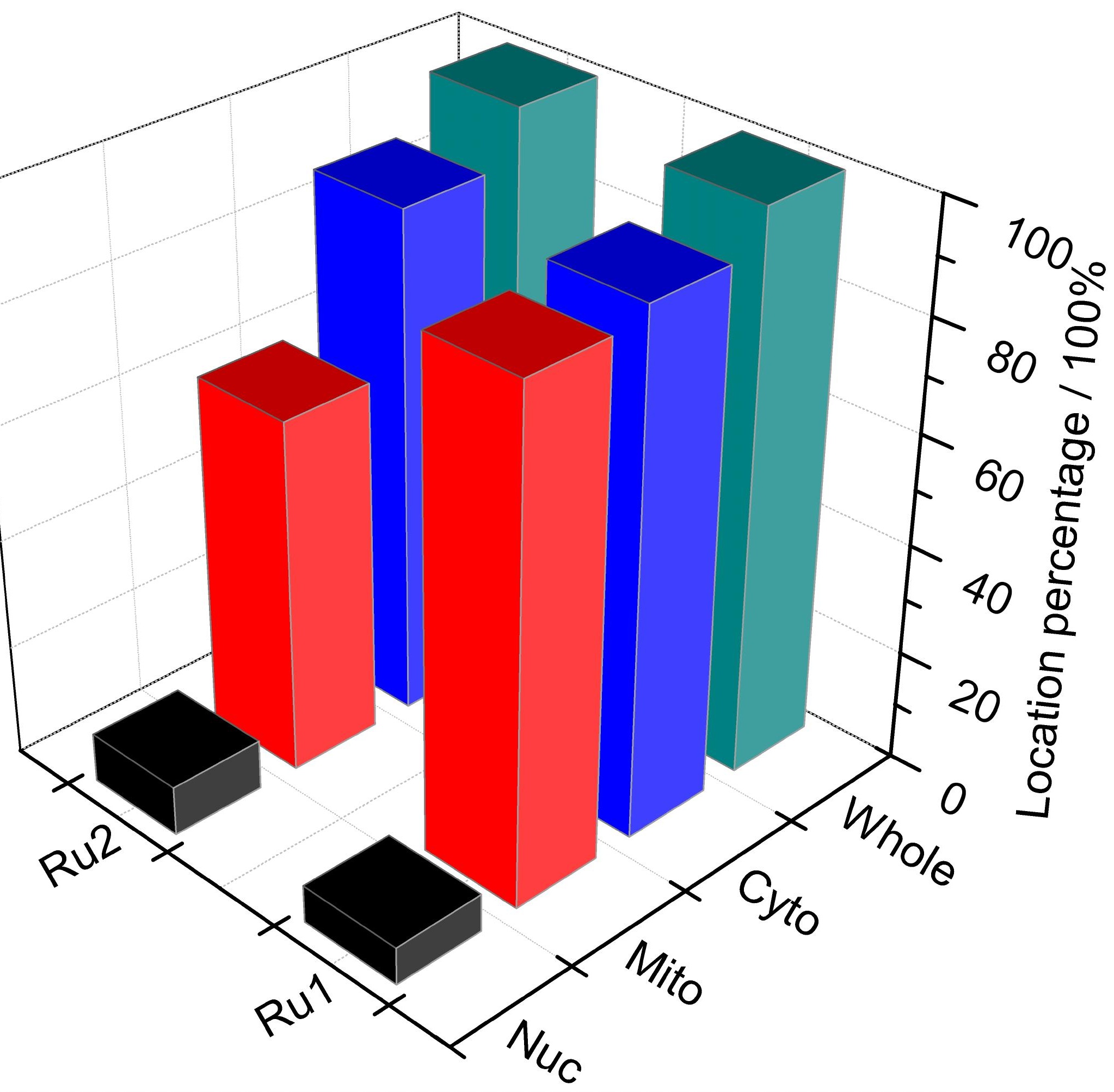




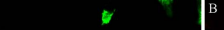

E.

$Q 8$

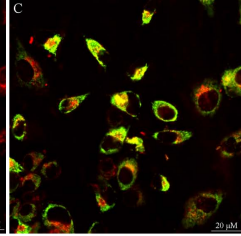


MTG

Control

+CCCP
Ru

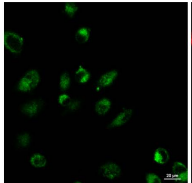

Overlay
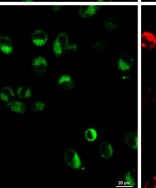

xes

(8) $y^{2}, 9$

6

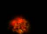

$\boldsymbol{Q}$

13

a

* 0 a

a

b. 1

$m$ is 

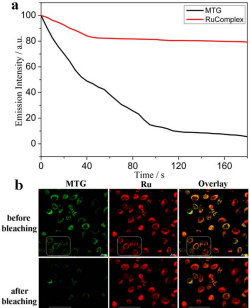

MTG

Ru

Overlay

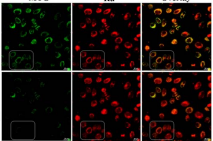




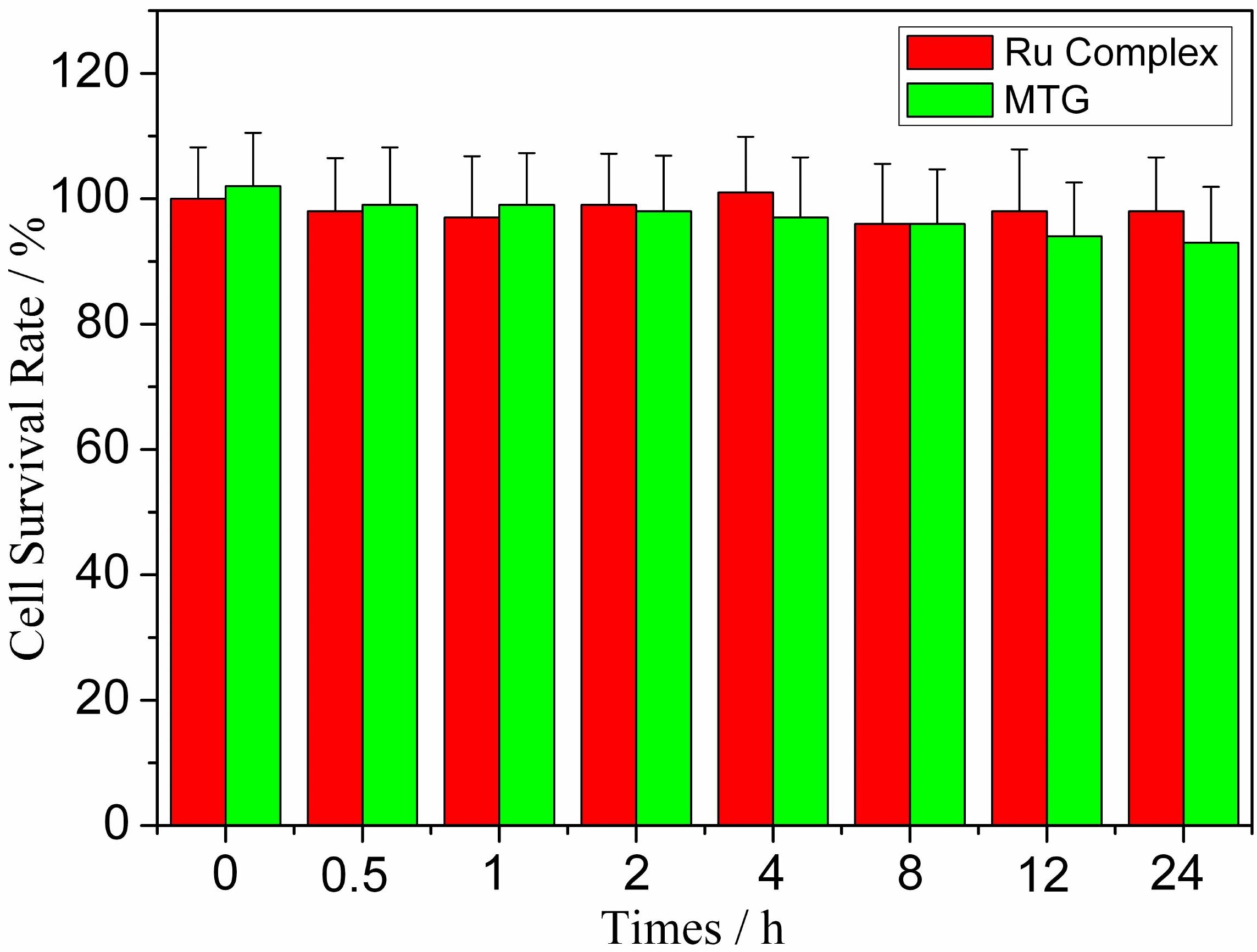


Table 1 Crystal data and structure refinement for Ru1

\begin{tabular}{|c|c|}
\hline Identification code & Ru1 \\
\hline Empirical formula & $\mathrm{C}_{45} \mathrm{H}_{30} \mathrm{Cl}_{2} \mathrm{~N}_{8} \mathrm{O}_{9} \mathrm{Ru}$ \\
\hline Formula weight & 998.74 \\
\hline Temperature/K & $298(2)$ \\
\hline Crystal system & Triclinic \\
\hline Space group & P-1 \\
\hline$a / \AA$ & $14.3118(8)$ \\
\hline$b / \AA$ & $17.6137(12)$ \\
\hline$c / \AA ̊$ & $18.7468(13)$ \\
\hline$\alpha /{ }^{\circ}$ & $77.629(6)$ \\
\hline$\beta /{ }^{\circ}$ & $76.794(6)$ \\
\hline$\gamma /{ }^{\circ}$ & $77.966(6)$ \\
\hline Volume/Å3 & $4430.3(5)$ \\
\hline$Z$ & 2 \\
\hline$\rho_{\text {calc }} / \mathrm{g} \mathrm{cm}^{-3}$ & 1.497 \\
\hline$\mu / \mathrm{mm}^{-1}$ & 4.529 \\
\hline$F(000)$ & 1926 \\
\hline Crystal size $/ \mathrm{mm}^{3}$ & $0.25 \times 0.19 \times 0.14$ \\
\hline Radiation & $\mathrm{Cu}-\mathrm{Ka}(\lambda=0.71073)$ \\
\hline $2 \theta$ range for data collection $/{ }^{\circ}$ & 5.22 to 122.62 \\
\hline Index ranges & $\begin{array}{l}-16 \leq \mathrm{h} \leq 16,-19 \leq \mathrm{k} \leq 20,-20 \leq 1 \\
\leq 21\end{array}$ \\
\hline Reflections collected & 13665 \\
\hline Independent reflections & $\begin{array}{l}9205\left[R_{\text {int }}=0.0499, R_{\text {sigma }}=\right. \\
0.0727]\end{array}$ \\
\hline Data/restraints/parameters & $13234 / 10 / 1127$ \\
\hline Goodness-of-fit on $F^{2}$ & 1.063 \\
\hline Final $R$ indexes $[I \geq 2 \sigma(\mathrm{I})]$ & $R_{1}=0.0744, \mathrm{w} R_{2}=0.2035$ \\
\hline Final $R$ indexes [all data] & $R_{1}=0.0993, \mathrm{w} R_{2}=0.2286$ \\
\hline
\end{tabular}


Table 2 Selected bond lengths $(\AA)$ and angles $\left(^{\circ}\right)$ for Ru1

\begin{tabular}{llllll}
\hline Ru1-N5 & $2.043(7)$ & N4-Ru1-N2 & $90.6(2)$ & N12-Ru2-N10 & $91.8(2)$ \\
Ru1-N4 & $2.044(6)$ & N5-Ru1-N1 & $89.4(3)$ & N9-Ru2-N10 & $80.3(2)$ \\
Ru1-N2 & $2.063(6)$ & N4-Ru1-N1 & $96.5(2)$ & N12-Ru2-N11 & $79.8(3)$ \\
Ru1-N1 & $2.074(6)$ & N2-Ru1-N1 & $79.6(2)$ & N9-Ru2-N11 & $168.3(2)$ \\
Ru1-N6 & $2.075(7)$ & N5-Ru1-N6 & $80.9(3)$ & N10-Ru2-N11 & $90.5(2)$ \\
Ru1-N3 & $2.079(6)$ & N4-Ru1-N6 & $92.6(3)$ & N12-Ru2-N14 & $169.5(2)$ \\
Ru2-N12 & $2.056(6)$ & N2-Ru1-N6 & $172.4(2)$ & N9-Ru2-N14 & $93.7(2)$ \\
Ru2-N9 & $2.056(6)$ & N1-Ru1-N6 & $93.2(2)$ & N10-Ru2-N14 & $97.1(3)$ \\
Ru2-N10 & $2.067(6)$ & N5-Ru1-N3 & $95.5(3)$ & N11-Ru2-N14 & $94.7(3)$ \\
Ru2-N11 & $2.081(7)$ & N4-Ru1-N3 & $79.4(2)$ & N12-Ru2-N13 & $92.5(2)$ \\
Ru2-N14 & $2.094(7)$ & N2-Ru1-N3 & $92.4(2)$ & N9-Ru2-N13 & $94.6(2)$ \\
Ru2-N13 & $2.100(7)$ & N1-Ru1-N3 & $171.1(2)$ & N10-Ru2-N13 & $173.5(2)$ \\
N5-Ru1-N4 & $171.4(3)$ & N6-Ru1-N3 & $94.9(2)$ & N11-Ru2-N13 & $95.1(2)$ \\
N5-Ru1-N2 & $96.6(3)$ & N12-Ru2-N9 & $93.2(3)$ & N14-Ru2-N13 & $79.1(3)$ \\
\hline
\end{tabular}




\section{Graphical abstract}

A Ruthenium(II) complex with benzofuran group was found to possess a superior capacity to selectively accumulate in mitochondria, superior photostability, low cytotoxicity at the imaging concentration, high resistance to the loss of mitochondrial membrane potential and good water solubility. Thus, this complex demonstrates good potential in mitochondrial imaging in living cells.
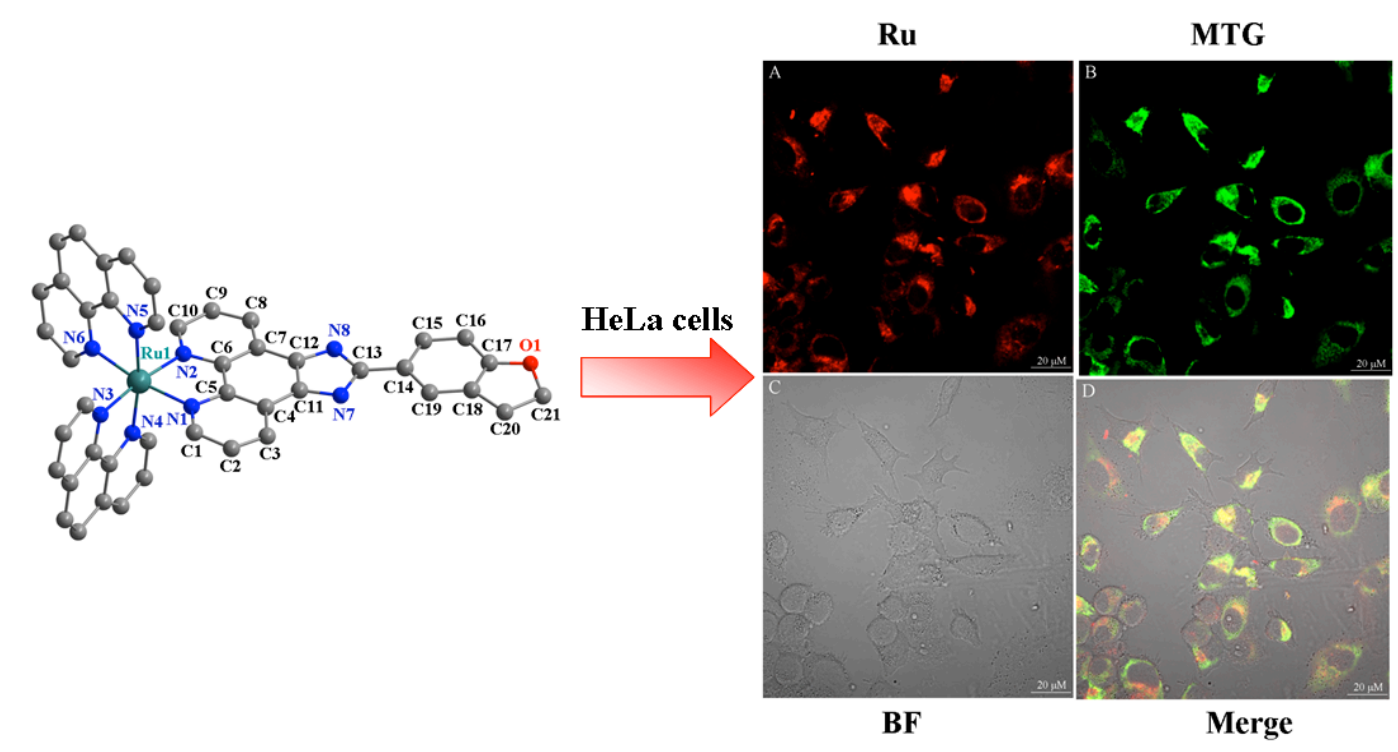